\title{
PROFESSOR, INTELECTUAL E LEITOR
}

\author{
Daniela Bunn* \\ Fabiana Cardoso Fidelis ${ }^{* *}$
}

\section{Introdução}

Este texto surge da leitura e discussão de "Professores, intelectuais e escritores", de Barthes; e de "Sistemas de ensino e sistemas de pensamento", de Bourdieu. Fomos convidadas, pela professora Tânia Regina Ramos, no curso de Pós-graduação em Literatura da UFSC, a atravessar os textos lidos para a sua disciplina por meio de conversas trocadas em e-mails. A conversa e a escrita fluíram muito agradavelmente entre nós duas, em parte pelas descobertas de coincidências bibliográficas, em parte pela distância geográfica onde nos encontrávamos, confirmando como o texto escrito, virtual ou impresso, ainda tem a finalidade de aproximar distâncias e ligar espaços. Os e-mails foram trocados durante um pouco mais de um mês e, posteriormente, reorganizados para constituir este texto, mas procuramos manter aqui as características da conversa para além da teoria e das experiências discutidas.

Foram intermináveis diálogos pela internet sobre textos estudados em sala de aula. Escritas fluídas como água de uma torneira aberta. Correspondências eletrônicas intermináveis num curto período que totalizaram mais de 40 páginas de reflexões sobre escritores, intelectuais, professores e sobre onde nos encaixamos no meio dessa transitoriedade.

Fabiana,

Barthes nos diz que a linguagem é potência, falar é exercer uma vontade de poder. E escrever? É potência? Se é potência, logo é linguagem (não 
verbal)? É então uma potência-reversível? Você não pode saber quantas letras deletei antes de te mandar estes rabiscos. Pra mim são rabiscos, mas parece estranho rabiscar no computador.... Sabe, a relação docente de que fala Barthes é parecida com a relação de quem envia e recebe um email: expor um saber que nunca se sabe como é recebido. Não dá pra saber a reação da pessoa, as caretas, os trejeitos... Parece também haver o contrato imaginário implícito 1 .

Tem algo errado nas afirmações acima... Dá pra me ajudar? Deu pra confundir? O objetivo era esse, mas se pra ti está tudo certo, acho então que te enquadras como intelectual... porque eu estou meio confusa, querendo te confundir... E você? Sabe qual o é o seu lugar?

Dani

31 mar. 2007

Dani,

Esta troca de e-mails será uma boa oportunidade para discutir as leituras que estamos fazendo e para nos conhecermos melhor. Embora não fosse a minha intenção inicial, neste e-mail acabo fazendo um retrospecto da minha vida. Afinal como não pensar em minha trajetória profissional ao refletir sobre "intelectuais e professores"? Espero que tenhas paciência de ler.

Para ser professor, basta nossa tendência irreprimível de explicar e querer que o outro entenda a resposta sempre que nos fazem uma pergunta relativa à nossa área. Um engenheiro, por exemplo, responde as perguntas atuando ou, quando muito, demonstrando - ele nunca quer "ensinar", a menos que tenha tendências para o magistério...

Tornei-me professora e agora sou professora universitária. Sobre isso me questiono todos os dias - tanto sobre o meu papel como professora quanto sobre o papel da universidade. Agora me aproximo mais do texto de Barthes e das anotações que fiz ao ler...

Gostaria de discutir o "contrato implícito entre o docente e o discente". Bem lembra Barthes que esse contrato imaginário não contradiz a "determinação econômica que leva o estudante a buscar uma carreira e o professor a honrar um emprego". ${ }^{2}$ Isso é importante porque, em última 
instância, esta é a profissão e emprego que temos e temos de "honrá-lo".

Proponho-me a analisar os itens do contrato: ${ }^{3}$

O docente pede ao discente: "1) reconhecê-lo num papel, seja ele qual for $[\ldots] "$

Sim. Bem ou mal, cumprimos ainda um papel como professores - a autoridade, ainda que não seja mais a mesma quanto ao "respeito" e status reservados aos professores no passado, ainda vigora, na medida em que o professor tem o poder de aprovação ou reprovação (por mais tênue que seja este poder). Além disso, sua formação (por mais precária que tenha sido) garante-lhe uma ascendência diante do aluno - afinal o professor chegou antes,estudou antes e passou por uma quantidade de anos de estudo sobre o que leciona.

O discente pede ao docente: "1) conduzi-lo a uma boa integração profissional;"

O professor não tem, em geral, cumprido com esse papel, visto que não há no estudo garantias de profissionalização, ou melhor, de uma "carreira", como diz Barthes anteriormente. A titulação não garante nem competência nem atuação na área - na graduação formam-se profissionais generalistas, que, mesmo com o título, terão de fazer uma especialização ou outros cursos de formação (ouvi falar que a moda mais recente é fazer duas graduações...).

O docente pede ao discente: "2) rendê-lo, estendê-lo, levar ao longe as suas idéias, o seu estilo;"

De fato, temos esse desejo quando somos professores - acreditamos em algo que queremos que nosso aluno acredite também, mais ainda se formamos professores, como é o caso dos cursos de licenciatura. Queremos, de certa forma, que eles sejam um pouco como nós, ainda que não nos consideremos um exemplo. E se trabalhamos com leitura, escrita e cálculos, queremos que nossos alunos leiam e gostem de ler, bem como de escrever e calcular. Nos sentimos frustrados quando, no final do semestre, o aluno não produziu da forma como poderia. É uma afronta pessoal, pois ele desdenhou o conhecimento que lhe oferecemos e que queríamos que ele levasse adiante, para a sua vida, para além de ser aprovado na disciplina.

E o discente espera do docente: "2) preencher os papéis tradicionalmente afetos ao professor (autoridade científica, transmissão de um capital de saber, etc." 
A maior queixa que um aluno pode fazer de um professor é a de que ele não sabe o que ensina. Cada vez mais os professores, tanto das universidades particulares quanto das públicas, têm de ministrar disciplinas que apenas margeiam sua área de estudo e pesquisa. Nas particulares, por atender as necessidades de cumprir a carga horária e por não haver muitos professores; nas públicas, isso ocorre principalmente com os professores substitutos, que têm de dar conta de um leque de disciplinas de maneira emergencial. Nem sempre o professor tem a autoridade científica que o aluno exige - então há as reclamações, as insatisfações...

O docente pede ao discente: "3) deixar-se seduzir, prestar-se a um relacionamento amoroso [...]"

Paro um momento e procuro um pequeno livro que tenho de Paulo Freire, "Pedagogia da autonomia". O livro aborda três teses em três capítulos: "Não há docência sem discência", "Ensinar não é transferir conhecimento", "Ensinar é uma especificidade humana". Chama-me a atenção a primeira tese, pois é justamente sobre isso que Barthes fala quando se refere ao contrato - professor e aluno se pressupõem, se desejam. No último item do terceiro capítulo, encontro: "Ensinar exige querer bem aos educandos".

Segundo Freire, "Esta abertura ao querer bem não significa, na verdade, que, porque professor, me obrigo a querer bem a todos os alunos de maneira igual. Significa, de fato, que a afetividade não me assusta, que não tenho medo de expressá-la." ${ }^{4}$ Esse querer bem diz respeito à especificidade de ser humano, e o ensinar faz parte dessa especificidade. As outras espécies de seres vivos transmitem comportamentos, mas não "ensinam", como apenas os seres humanos fazem. Ironicamente, espera-se essa dimensão humana no ensino, mas, às vezes, o professor mais valorizado pelo aluno é aquele que transmite o conhecimento, pois, segundo Paulo Freire, a ideologia neoliberal "[...] se forja uma educação friamente tecnicista e se requer um educador exímio na tarefa de acomodação ao mundo e não de sua transformação. Um educador com muito pouco de formador, com muito mais de treinador, de transferidor de saberes, de exercitador de destrezas."5

Barthes coloca como desejo do professor o relacionamento amoroso, enquanto Freire o apresenta como uma característica do "bom docente", que é não ter medo da afetividade. Fiquei pensando sobre como Barthes e Freire se aproximam ao falarem do desejo, da linguagem.

Por último, o docente pede ao discente: "4) enfim, permitir-lhe honrar o 
contrato que ele próprio estabeleceu com o empregador, isto é, com a sociedade: o discente é a peça de uma prática (retribuída), o objeto de um ofício, a matéria de uma produção (ainda que delicada de definir-se)."

$\mathrm{O}$ aluno pode ser um obstáculo ao professor no exercício de sua profissão. Entretanto, curiosamente o mais comum é que o professor seja um empecilho para a formação do aluno. Principalmente nas universidades particulares, o aluno ingressa na faculdade com o objetivo de cumprir determinado currículo em determinado tempo, e o professor é aquele que pode atravancá-lo nesse objetivo, dificultando-o, ameaçando-o com reprovações, causando transtornos.

Pede o discente ao docente: "3) entregar os segredos de uma técnica (de pesquisa, de exame, etc.); 4) [...] ser um iniciador de asceses, um guru; 5) representar um 'movimento de idéias' [...]; 6) admiti-lo a ele, discente, na cumplicidade de uma linguagem particular; 7) para aqueles que tem o fantasma da tese [...], garantir a realidade desse fantasma; 8) [...] que seja um distribuidor de serviços: assina matrículas, atestados, etc."

Mesmo analisando item por item no contrato proposto por Barthes, não tenho a clareza de sua pertinência no momento atual e na realidade da universidade brasileira. $\mathrm{O}$ que quero é repensar o papel da universidade, do ensino, da educação e, no nosso caso específico, do ensino de literatura (se é que ensinar a literatura é possível), seja por esta troca de e-mails, na disciplina da Tânia ou por outras leituras e escritas.

Então, volto ao teu e-mail e leio sobre a potência da escrita e a confusão em que queres me meter: "Barthes nos diz que a linguagem é potência, falar é exercer uma vontade de poder. E escrever? É potência? Se é potência logo é linguagem (não verbal)? É então uma potência-reversível?"

Escrever é uma atividade essencialmente solitária, assim como a leitura. Talvez seja a "vontade de poder" a que Barthes se refere e que tu trazes para o e-mail: "Você não pode saber quantas letras deletei antes de te mandar estes rabiscos..." Quantas letras foram deletadas não sei, mas, como este e qualquer outro, um texto é sempre inacabado e sujeito à alteração, ainda mais com as facilidades que o computador permite - que o diga minha função de revisora de textos. Sempre é possível encontrar algo para melhorar ou modificar, mas depois de pronto, enviado por e-mail ou publicado, o texto se constitui na sua ilusão de linearidade e unicidade.

Tu dizes: "Sabe que a relação docente de que fala Barthes é parecida 
com a relação de quem envia e recebe um e-mail: expor um saber que nunca se sabe como é recebido. Não dá pra saber a reação da pessoa, as caretas, os trejeitos... Parece também haver o contrato imaginário implícito."

O contrato imaginário implícito na linguagem (discutido por vários estudiosos e suas linhas teóricas) dá muito "pano para manga". Escrever, tanto aqui como em qualquer outra situação ou outro texto, é possibilitar novas vozes, que pegarão o nosso dito para desdobrá-lo: "[...] escrever é oferecer, desde o primeiro momento, essa última réplica ao outro."6

Boa semana!

Fabiana

1 abr. 2007

É um contrato quebrado mesmo, pois muitas vezes o professor não quer ensinar e o aluno não quer aprender. Achei interessante a ótica do Barthes quando ele retorce a figura do professor de observador para observado. E quando acontece o contrário é muito interessante, ao invés de o professor instigar o aluno, o aluno instiga o professor, pois a imagem do professor ideal também é almejada. O professor é sempre muito carrasco ou muito largado, muito teórico ou inconsistente, acha que só existe a disciplina dele naquele semestre ou não dá a mínima se os alunos estão lendo ou não. Não tem escapatória.

O feriado foi longo e a leitura de Bourdieu adiada. O sociólogo francês fez-me recordar as leituras sobre Lévi-Strauss no começo da graduação e, por conseguinte, as primeiras sobre/de Benjamin, Candido, Orígenes Lessa, e a cadeia desenfreada de ismos.

As técnicas, os ritos do ensino, os métodos e esquemas "metodicamente organizados da Escola" (que organizam o pensamento) dos quais fala LéviStrauss - eu achei que só pertencessem ao universo escolar. Os resquícios desse sistema arrastam-se universidade afora (vindo tanto de alguns professores como, e principalmente, dos alunos). Revendo o papel da escola como transmissora da cultura e formadora de hábitos ${ }^{7}$, penso logo nos maus hábitos que adquirimos, resumos sem senso, questionários decorados (e olha que não tinha internet naquela época, pelo menos copiávamos à mão).

Bourdieu vê, de certa forma, como "ingênuo" o modo como Durkheim 
ignora o papel da Educação e, conseqüentemente, da escola como instituição (aqui lembro Barthes) a partir de sua perspectiva antropológica. O sistema de ensino que fala Bourdieu, com seus "indivíduos programados" (modelados, regrados, cúmplices com seus pares, com seus "lotes de temas comuns") pertencentes à tradição humanista, ao ensino tradicional, opõese ao ensino especializado - um sistema que consagra esquemas e temas. Uma das hipóteses de Bourdieu é que as escolas de pensamentos poderiam conter os pensamentos de escola, como se o primeiro remetesse ao sistema de pensamento e o segundo ao sistema de ensino que batiza seu artigo. Lembra que "cada sujeito deve ao tipo de aprendizagem escolar que recebeu um conjunto de esquemas fundamentais"

Esquemas, esquemas, esquemas, roteiros, roteiros, roteiros... ESQUEMAS: quais são os teus esquemas apre(e)ndidos? E os meus? Comungam simplesmente por serem da mesma época? Esquemas de uma universidade diferente, ou da mesma só que em anos diferentes, ou no mesmo semestre só que com professores diferentes ou com professores iguais em turmas diferentes = aquisição de esquemas diferentes, produção de esquemas inconscientes. Esquemas, esquemas, diferentes? Iguais?

Partindo do princípio da clarificação, vamos tentar melhor nosso entendimento. Bourdieu invoca Kurt Lewin, "a realidade não é absoluta", e difere de acordo com o grupo ao qual pertencemos. Isto me reporta às discussões com os alunos nas aulas de Metodologia do Ensino da UFSC sobre cultura/estranhamento (leva-me a dois textos de que gosto: "Você tem cultura?", do Roberto da Matta, e "O que é etnocentrismo", de Everardo Rocha, sugiro a leitura, são textos curtinhos). Várias perguntas vêm à mente sobre cultura, escola, relação sujeito/cultura, que cultura? A cultura de uma determinada classe?

Pensando nisso, achei válida a discussão sobre conhecimento adquirido e modo de aquisição do conhecimento. Acho que poderíamos abrir um pouco a discussão mais sobre este relacionamento individual com a cultura e a maneira como esta foi adquirida; e pensar no sistema brasileiro de ensino e a nossa aquisição dos esquemas - mero automatismo, sem ser conscientemente aprendidos e dominados pelos alunos. Isto parece acontecer muito, principalmente nos anos escolares. Poderíamos pensar num ponto de apoio entre Barthes e Bourdieu. 
Até breve,

Dani

3 abr. 2007

\section{Oi Dani,}

Li mais uma vez "Escritores, intelectuais e professores" e ao chegar ao final do texto fiquei me perguntando sobre como mestrandos, doutorandos e às vezes até graduandos (estes bem mais raramente) costumam dizer: "Tenho 300 páginas para ler por semana", "Tenho cinco mil páginas para ler em cada disciplina”. É bem comum ouvirmos estas afirmações. Sempre achei estranha essa forma de medir o estudo - por meio da quantidade de páginas e, além disso, bastante excessivas as quantidades mencionadas. Que tipo de leitura dinâmica é essa? A pessoa devora os livros e artigos, mas como os digere? Não dá dor de estômago? O organismo não rejeita? Lendo o texto do Barthes novamente, cheguei à conclusão de que seria possível passar a disciplina toda com apenas este texto e todas as implicações do que ele apresenta e como apresenta. Fiquei pensando também em nossas conversas por e-mail e sobre o que deixamos de falar (escrever) a respeito do texto - o não-mencionado e o silêncio, como se não existisse. Eu escolhi já de início escrever sobre o contrato entre docente e discente; tu escreveste sobre a relação invertida, que coloca o professor como aquele que é psicanalizado. E tudo o mais? O papel da crítica? A diferença entre fala e escritura? Aquestão da pesquisa? A relação entre psicanálise e marxismo? [...]?, [...]?, [...]?

Essa falta, que mostra o não-lido, traz implicações para uma teorização da leitura - quantos e quais tipos de leituras podem ser feitos? Falamos em graus e níveis de leitura, que, segundo Barthes ${ }^{10}$, não podem ser elencados em uma lista, pois não há como limitar a "profundeza e a dispersão da leitura". Pode-se ir ao "infinito [...] declarar que tudo é legível" quanto se pode dizer que em todo o texto há algo de ilegível. Essa impossibilidade de delimitar a leitura é ela mesma congênita à leitura, segundo Barthes, pois "[...] algo, estatutariamente, viria atrapalhar a análise dos objetos e dos níveis de leitura [...]". Então, quando vemos nossos amigos e colegas lendo uma infinidade de páginas ou quando colocamos nossos alunos a ler uma 
quantidade demasiada de textos, literários ou teóricos, pergunto: "Que leitura é essa que se quer no ensino?" E, para trazer o tema para a nossa disciplina: "Que leitura é essa que se quer no ensino de literatura?" Basta para nós, como professores, que os alunos leiam e conheçam as obras - a sua narrativa (o que em algumas ocasiões já é difícil de conseguir) - ou quer-se uma leitura crítica, tendo provisoriamente aqui a definição de Barthes para "crítica": "pôr em crise"11. No caso, pôr em crise a linguagem do texto.

À parte desse primeiro questionamento, quero retomar o teu e-mail da semana passada. Quando o li, fiz anotações à mão, para não perder de vista tudo que pensei em responder. Minha vontade era responder na hora, mas tive de conter a escrita que quase jorrava, para enviar um texto mais organizado e coeso - escrito, lido e reescrito.

Costumo dizer para os meus alunos da licenciatura que eles devem desconfiar de si mesmos, pois eles "deram certo na escola". Estamos na universidade (nos formamos, portanto, no ensino fundamental e médio, sem sermos evadidos) e, ainda por cima, queremos voltar para a escola, como professores. A escola foi positiva para nós, embora não tenha sido para muitos que ficaram no caminho. Voltando para ela, tendemos a repetir os modelos que tivemos (pesquisas mostram como os professores recémformados tendem a dar aula dos mesmos conteúdos que tiveram, apesar das diferentes abordagens de conteúdos e métodos de suas faculdades).

É difícil para nós, professores, pensarmos o sistema escolar, os "esquemas" que envolvem o ensino da mesma forma que é difícil, como afirma Bourdieu, para o etnólogo "[...] tomar como objeto de pensamento os esquemas que organizam o seu próprio pensamento."12 Nós continuamos no ensino e questionamos as atitudes dos alunos, conforme tu colocas: "O processo de mudança de hábito é difícil nos primeiros semestres, às vezes perdura até os últimos, vejo isso principalmente quando ouço: 'Professora, você tem que ser mais carrasca.'", o que nos leva a questionar as nossas próprias atitudes.

É importante lembrar que questionamos sempre de dentro. Espremidos entre o desejo e o dever, entre o "contrato imaginário" proposto por Barthes e a prática, afinal temos a "[...] determinação econômica que leva o estudante a buscar uma carreira e o professor a honrar um emprego."13

Uma vez fiz a seguinte pergunta a um palestrante que ministrou uma oficina sobre produção de textos: "Por que nem mesmo na faculdade 
conseguimos uma produção de textos efetiva, de forma que os alunos se preocupem com o que escrevem e lêem, promovendo um debate?" A resposta foi a de que, como os alunos vêm de um sistema de ensino em que a repetição foi a tônica, é difícil mudar isso instantaneamente na faculdade. Fiquei aliviada com esse esclarecimento, pois sempre me sentia incompetente por não conseguir fazer na universidade algo muito diferente do que a escola já faz (e que é bem ruim).

Será que não pensamos assim por que somos professores e alunos que "deram certo"? O que pensam os alunos? Por que muitos deles estão insatisfeitos com seus cursos e com seus professores? O que querem os alunos? Por que fazem uma faculdade, especialmente de Letras? Talvez tenhamos respostas diferentes de alunos de universidades públicas e particulares. Essas perguntas são importantes porque as respostas a elas dizem bastante sobre o ensino de literatura, sobre o ensino da escrita e da leitura - questões que nos preocupam.

A crítica que Bourdieu faz a Durkheim é a de que ele ignorou a "função de integração cultural" da escola, descrevendo apenas a "função de integração moral". Para Bourdieu, "[...] do mesmo modo que a religião nas sociedades primitivas, a cultura escolar propicia aos indivíduos um corpo comum de categorias de pensamento que tornam possível a comunicação."14

Pergunto: Como a escola (principalmente a pública) cumpre esse papel hoje, na medida em que se recusa a trabalhar com a cultura/conhecimento erudito? Já respondendo, na verdade ela cumpre ainda da mesma forma o papel, pois o "corpo comum de categorias de pensamento" fica restrito à classe social a que pertencem os professores e alunos. A escola garante que esse aluno fique nesse "corpo comum" de seu meio e que não passe a fazer parte ou a conhecer as categorias de pensamento por assim dizer "eruditas". E onde fica a literatura nesse papel da escola? É muito importante para a própria sociedade que a literatura seja sonegada aos alunos e à população em geral, pois ela tem um papel subversivo não interessante quem lê e escreve pode ser uma pessoa perigosa.

Pergunto-me também se esse "código comum", que, segundo Bourdieu, "[...] permite a todos os detentores deste código associar o mesmo sentido às mesmas palavras [...]"15, transmitido pela Escola não seria atualmente transmitido pela mídia? Se Durkheim vivesse hoje falaria do papel 
moralizante dos meios de comunicação. Talvez fosse necessário ler os textos mais recentes de Bourdieu para dialogar com o "Sistemas de ensino e sistemas de pensamento".

Qual a definição do termo "escolas de pensamento" neste texto? Encontro na página 209 o que mais se aproxima de uma definição: "[...] poder-se-ia definir para cada época, além de um lote de temas comuns, uma constelação particular de esquemas dominantes e um número de 'perfis epistemológicos' [...] correspondente às escolas de pensamento."16 Adiante Bourdieu diz que um pensador participa de sua sociedade e de sua época por suas aprendizagens intelectuais e por sua formação escolar. Por mais que me esforce, continuo sem entender o trecho que tu disseste que poderia ser melhor explorado: "[...] as escolas de pensamento poderiam conter pensamentos de escola de modo mais freqüente do que possui."17

Barthes se refere, no contrato imaginário entre docente e discente, que um dos desejos do discente é de que o docente admita-o "[...] na cumplicidade de uma linguagem particular", pois o docente deve "[...] representar um 'movimento de idéias', uma Escola, uma Causa, e dela ser o porta-voz."18 Aproxima-se muito do que Bourdieu propõe como o papel da escola e dos sistemas de ensino.

Acho que as perguntas que colocas dizem respeito também à definição de cultura. Podemos falar em cultura, ou teríamos que falar em culturas? Mesmo em um mesmo ambiente de ensino, há uma cultura e uma linguagem comum, como propõe Bourdieu?

Como tu observas, Bourdieu, remontando a Hursserl, afirma que "Ter acesso à cultura é o mesmo que ter acesso a uma cultura, a cultura de uma classe de uma nação."19 Mas teríamos no Brasil uma classe? Teríamos uma cultura dominante transmitida pela escola?

Volto à pergunta: Que cultura(s) a escola tem como linguagem comum? Pergunto isso porque a dita "cultura erudita" não está mais na escola. Aliás, o que é trabalhado, estudado na escola hoje? Estuda-se alguma coisa? Aprende-se alguma coisa? Em relação à leitura e à escrita, depois da alfabetização, será que não se aprende "apesar da escola" e não por causa dela?

Fiquei surpresa quando tu citaste a palavra "jorrar" em aula, pois quase a censurei quando escrevi. Achei-a um tanto forte e um quanto "obscena". A minha escrita tende muito mais a ser contida do que "jorrar". Talvez por 
estes textos terem o formato de e-mails, sujeitos a uma reelaboração posterior, tenham esse caráter de jorro.

Abraços,

Fabiana

15 abr. 2007

Fabiana, gosto da frase "queremos voltar para a escola como professores" e concordo com a pesquisa que mencionas que "mostram como os professores recém-formados tendem a dar aula dos mesmos conteúdos que tiveram, apesar das diferentes abordagens de conteúdos e métodos de suas faculdades". Às vezes, por se sentir tão perdido ou com medo de arriscar ou com preguiça mesmo, o professor iniciante imita os atos que lhe passaram pela vida.

Voltando: "Por que fazem uma faculdade, especialmente de Letras? Talvez tenhamos respostas diferentes de alunos de universidades públicas e particulares". As respostas podem ser diferentes, mas as problemáticas não. Ontem na palestra falei um pouco disso - a responsabilidade que eles têm de contribuir para a criação de nossas metodologias, de aumentar o repertório, de pensar, criar, não só reproduzir. Tenho orgulho de ter orientado alguns estágios muito híbridos que trabalharam com diferentes leituras (papel, corpo, imagem), com um eixo temático os estagiários exploraram a potencialidade da leitura de várias formas. Gosto muito de trabalhar com artes plásticas e performance nas aulas, acho a possibilidade de ler imagens algo fascinante.

A palavra JORRAR chamou mesmo a minha atenção, talvez porque dentro deste discurso, de certa forma contido e revisado, tenha aparecido esta palavra tão erótica e espontânea. Às vezes censurarmos também muitas idéias que achamos bobas...

A seguir (re)escrevo fragmentos que jorraram de alguns textos. Colocoos aqui como entradas para novos pensamentos, destaques, idéias líquidas para finalizar nosso texto.

Jobim $^{20}$ fala do papel como professores de literatura, da compartimentalização das disciplinas, do esforço reflexivo, da ênfase na teoria e questiona quais as conseqüências práticas que a teoria teve em 
nossa docência de literatura. Uma pergunta que deixo no ar. Já Cristina Melo $^{21}$ questiona a apropriação escolar da literatura, a ascensão das novas teorias de abordagem, a história da literatura versus a literatura, a mudança do tratamento com o LEITOR, e pertinentemente a LEITURA INTEGRAL, as estratégias didáticas e o estudo escolar da literatura. Vale lembrar o texto de Marisa Lajolo ${ }^{22}$ que nos dá um histórico do livro didático, da escola e do ensino no Brasil.

Cyana Leahy-Dios discute a microestrutura da sala de aula, a história da educação moderna no Brasil (a partir de 1930) e a conseqüente mudança de paradigma: da memorização à LEITURA COMO PRAZER, e destaco "o papel original de leitura como modelo e prazer que os influenciou a se tornarem professores de literatura não é vivenciado por seus alunos, indicando que algo mudou, mais que a distância socioeconômica entre as gerações"23. A autora fala dos problemas nutritivos de formação (aliás, comecei a escrever um texto sobre isso), dos espaços dos autores contemporâneos, da educação literária e do educar para a leitura. "Atrair os alunos para a leitura" virou mágica. A autora dialoga implicitamente com Barthes e a discussão de professores/intelectuais. E a bandeja didática continua pouco nutritiva. ESTAMOS DE DIETA! A voz abafada dos estudantes de Letras que deveriam ajudar a construir o saber. Professores e alunos insatisfeitos com os programas, os conteúdos, as escolas, as provas, os alunos, os professores e sua própria competência. O papel da escola, acesso e necessidade, leituras marginais, os conteúdos como "fragmentos e retalhos", a prática mecanicista, o LIVRO DIDÁTICO - e a literatura como expressão artística é desconsiderada.

Dani

23 abr. 2007.

\section{Notas}

* Professora de Italiano, doutoranda em Teoria Literária no Programa de Pós-Graduação em Literatura da Universidade Federal de Santa Catarina. Participa do Grupo de Pesquisa Literatura e Ensino (UFSC). Ministra cursos e oficinas sobre literatura. E-mail: danibunn@yahoo.com.br.

** Doutoranda em Teoria Literária no Programa de Pós-Graduação em Literatura da Universidade Federal de Santa Catarina. Professora do Centro de Ciências de Comunicação 
e Artes da Universidade Comunitária Regional de Chapecó (SC). Líder do Grupo de Pesquisa Estudos Lingüísticos e Literários. E-mail: fabianafidelis@gmail.com.

${ }^{1}$ BARTHES, Roland. Escritores, intelectuais, professores. In: BARTHES, Roland. O rumor da língua. São Paulo: Brasiliense, 1988. p. 318-319.

2 Idem, ibidem.

${ }^{3}$ Os itens do contrato apresentados a seguir estão em BARTHES, Roland. Escritores, intelectuais, professores. In: BARTHES, Roland. O rumor da língua. São Paulo: Brasiliense, 1988. p. 318-319.

${ }^{4}$ FREIRE, Paulo. Pedagogia da autonomia: saberes necessários à prática educativa. São Paulo: Paz e Terra, 1997.

5 Idem, ibidem, p. 162

${ }^{6}$ BARTHES, Roland. São Paulo: Perspectiva, 2003, p. 15.

${ }^{7}$ BOURDIEU, Pierre. Sistemas de ensino e sistemas de pensamento. In: A economia das trocas simbólicas. São Paulo: Perspectiva, 1999, p. 206 e 211.

${ }^{8}$ Idem, ibidem, p. 206 e 209.

9 Idem, ibidem, p. 212

${ }^{10}$ BARTHES, Roland. Escritores, intelectuais, professores. In: O rumor da língua. São Paulo: Brasiliense, 1988, p. 45

${ }^{11}$ Idem, ibidem, p. 320 e 326.

12 BOURDIEU, Pierre. Sistemas de ensino e sistemas de pensamento. In: A economia das trocas simbólicas. São Paulo: Perspectiva, 1999, p. 204.

${ }^{13}$ BARTHES, Roland. Escritores, intelectuais, professores. In: O rumor da língua. São Paulo: Brasiliense, 1988, p. 318.

${ }^{14}$ BOURDIEU, Pierre. Sistemas de ensino e sistemas de pensamento. In: A economia das trocas simbólicas. São Paulo: Perspectiva, 1999, p. 205

15 Idem, ibidem, p. 206.

${ }^{16}$ Idem, ibidem, p. 209

${ }^{17}$ Idem, ibidem, p. 210

18 BARTHES, Roland. Escritores, intelectuais, professores. In: língua. São Paulo: Brasiliense, 1988, p. 318.

19 Idem, ibidem, p. 229.

${ }^{20}$ JOBIM, José Luís. A crítica da teoria: uma análise institucional. In: A poética do fundamento. Niterói: EDUFF, 1992.

${ }^{21}$ MELO, Cristina. Ensino de Literatura: perspectivas atuais. In: Formando uma sociedade leitora. Passo Fundo: EDIUP, 1999.

${ }^{22}$ LAJOLO, Marisa; ZILBERMAN; Regina. Livros didáticos, escolas e leituras. A formação da leitura no Brasil. São Paulo: Ática, 1996.

23 LEAHY-DIOS, Cyana. Analisando e interpretando os signos: signos brasileiros de educação literária. In: Educação literária como metáfora social. Niterói: EDUFF, 2000, p. 195 .

\section{Referências}

BARTHES, Roland. Escritores, intelectuais, professores. In: O rumor da língua. São Paulo: Brasiliense, 1988.

Crítica e verdade. São Paulo: Editora Perspectiva, 2003. 
BOURDIEU, Pierre. Sistemas de ensino e sistemas de pensamento. In: A economia das trocas simbólicas. São Paulo: Perspectiva, 1999.

DAMATTA, Roberto Augusto. Você tem cultura? Suplemento Cultural do Jornal da Embratel, 1981.

FREIRE, Paulo. Pedagogia da autonomia: saberes necessários à prática educativa. São Paulo: Paz e Terra, 1997.

JOBIM, José Luís. A crítica da teoria: uma análise institucional. In: A poética do fundamento. Niterói: EDUFF, 1992.

LAJOLO, Marisa; ZILBERMAN; Regina. Livros didáticos, escolas e leituras. In: . A formação da leitura no Brasil. São Paulo: Ática, 1996.

LEAHY-DIOS, Cyana. Analisando e interpretando os signos: signos brasileiros de educação literária. In: Educação literária como metáfora social. Niterói: EDUFF, 2000.

MELO, Cristina. Ensino de Literatura: perspectivas atuais. In: Formando uma sociedade leitora. Passo Fundo: EDIUP, 1999.

Recebido em 30/08/2007

Aceito em 10/10/2007 
DANIELA BUNN / FABIANA CARDOSO FIDELIS

Revista Pedagógica - UNOCHAPECÓ - Ano 10- n. 20 - jan./jun. 2008 